\title{
Ficus Carica and Vitellaria paradoxa Leaf Extracts as Inhibitors of Brass Corrosion in Acidic Medium
}

\author{
Alfred Ikpi Onen*1, Joseph Jacob ${ }^{2}$ \\ ${ }^{1}$ Department of Chemical Sciences, Federal University, Wukari, Taraba State, Nigeria \\ ${ }^{2}$ Department of Chemistry, Adamawa State University, Mubi, Adamawa State. Nigeria
}

\begin{abstract}
Corrosion inhibition of brass in $\mathrm{HCl}$ solutions by Ficuscarica and Vitellaria paradoxa leaf extracts was studied using weight loss measurements at 303,313, 323 and 333K. The adsorption of the inhibitors on brass surface follows Frumkin and Langmuir adsorption isotherms. The effect of temperature indicated that the corrosion rate and inhibition efficiency are temperature dependent in the range 303-333K. The kinetic data obtained indicate that the adsorption follows a first order type of reaction. Physisorption mechanism has been proposed for the inhibitors. Comparative assessment of the inhibitors revealed that Ficuscarica is a better inhibitor (highest $\% I_{E}=84.68 \%$ ) for brass corrosion than Vitellariaparadoxa (highest $I_{E}=77.66 \%$ ). The presence of alkaloids, glycosides, saponins and tannins (having $-\mathrm{C}=\mathrm{O}, \mathrm{C}-\mathrm{OH}, \mathrm{C}=\mathrm{C}, \mathrm{OH}-\mathrm{CH}_{3}$, e t c groups) in the plants extracts were found to have contributed greatly to the inhibition process by interacting with the brass surface.
\end{abstract}

Keywords: Corrosion inhibitors,Ficuscarica,Frumkin isotherm, Langmuir isotherm, Vitellariaparadoxa, Weight loss method.

\section{INTRODUCTION}

Copper and copper based alloys (e.g brass) are of considerable importance as they form the backbone of most modern industries. Brass has been widely used for shipboard condensers, power plant condensers and petrochemical heat exchangers $[1,2]$. Brass materials are relatively noble and for many applications have superior physical and mechanical properties, although it could present particular corrosion problems such as dezincification and pitting in chloride containing solutions leading to structural failure [3].

Most of the synthetic compounds (organic, inorganic e t c) used as inhibitors are expensive and equally source of several health hazards. Their toxic characteristics limit the field of their application. It becomes necessary to find less expensive and non-hazardous inhibitors for the protection of metals and alloys against corrosion. Several workers [4-8]have studied the possible replacement of these toxic and non-environmental friendly chemicals as corrosion inhibitors for metals/alloys in aggressive media from naturally occurring substances of plant origin.

Common fig (ficuscarica) is a small tree native to South West Asia. It belongs to the family, Moraceae. This edible fig is widely grown for its fruit and is commercially produced in the United States of America. This tree is also found in some parts of Northern Nigeria with Adamawa State inclusive. Several therapeutic effects such as hypoglycaemia [9] andhypotriglyceridemia [10] have been reported for different parts of Ficuscarica.

Vitellariaparadoxa also classified as Butyrospernumparkii and B. Paradoxa, commonly known as Shea tree, is a tree of the Sapotaceae family indigenous to Africa, occurring in Mali, Cameroon, Congo and Nigeria [11]. The Shea tree fruit consists of a thin, tart, nutritious pulp that surrounds a relatively large, oil-rich seed from which Shea butter is extracted. Throughout Africa, it is used extensively for food and medicinal purposes and a major source of dietary fat.

Ficuscarica leaf extract contains: alkaloids, flavonoids, and tannins. Similarly, phytochemical screening of Vitellariaparadoxa revealed the presence of carbohydrates (free reducing sugars, ketoses, pentoses, and starch), alkaloids, saponins, steroids and tannins e t c [12]. The use of Ficuscarica and Vitellariaparadoxa as corrosion inhibitors has not been reported. The present study is therefore aimed at evaluating the inhibitory properties of these new inhibitors - Ficuscarica (FC) and Vitellariaparadoxa (VP) leaves extracts on the corrosion of brass in $\mathrm{HCl}$ at $303,313,323$, and $333 \mathrm{~K}$ 
respectively using weight loss method. This is to ascertain their suitability as corrosion inhibitors and to compare the inhibitory effects of these plants extracts for brass corrosion.

\section{Materials AND Methods}

\subsection{Material Preparation}

The brass specimens also employed for the investigation is of composition: wt (\%) $65.3 \mathrm{Cu}, 34.44$ $\mathrm{Zn}, 0.1385 \mathrm{Fe}$ and $0.0635 \mathrm{Sn}$. The brass specimens were mechanically cut into coupons of dimension $5 \mathrm{~cm} \times 4 \mathrm{~cm}$ and thickness of $3.0 \mathrm{~mm}$ respectively with a hole drilled at one end for free suspension. The specimens were used as cut without further polishing to ensure reproducible surface. They were however degreased in ethanol, dried in propanone and stored in moisture-free desiccators before their use for the study.

Fresh leaves of Ficuscarica, FC and Vitellariaparadoxa, VP were collected, dried and pulverized into powdery form. The materials were dried in shade to enrich the active ingredients in them by reducing their moisture content. 200mg each of the fine powdered sample was dissolved in $400 \mathrm{~mL}$ distilled water and methanol in a round bottomed-flask. The first portion (the one in distilled water) was boiled, before it was decanted and filtered to produce the aqueous extract. The methanolic extract was concentrated on a rotary evaporator (RYC- R- 205D) at $45^{\circ} \mathrm{C}$ after the usual decantation and filtration.

Extracts concentrations (Ficuscarica and Vitellariaparadoxa) of $10^{1}$ to $10^{2} \mathrm{mg} / \mathrm{L}(10,30,50,70$, and $100 \mathrm{mg} / \mathrm{L}$ ) obtained by serial dilution were employed for the study. A concentration of $0.1-0.5 \mathrm{M} \mathrm{HCl}$ was also prepared and used as corrodent.

\subsection{Weight Loss Measurement}

Weight loss measurements were performed using procedure reported earlier by several authors $[5,6]$ but at 303, 313, 323 and 333K respectively. From the weight loss results, inhibition efficiencies (\% I) of the inhibitors, degree of surface coverage $(\theta)$ and corrosion rates for brass were calculated using modified equations by Eddy et al [13]. All measurements were performed in triplicate and mean values recorded.

\section{RESUlTS AND DisCUSSION}

\subsection{Effect of Corrodent Concentration and Temperature on Brass Corrosion}

Figure 1, Tables 1 and 2 show the variation of weight loss with time (days) for brass corrosion in $\mathrm{HCl}$ at $303 \mathrm{~K}$ without and with Ficuscarica (FC) and Vitellariaparadoxa (VP). The results show that the weight loss of brass in $\mathrm{HCl}$ increased with increasing acid concentration and temperature.

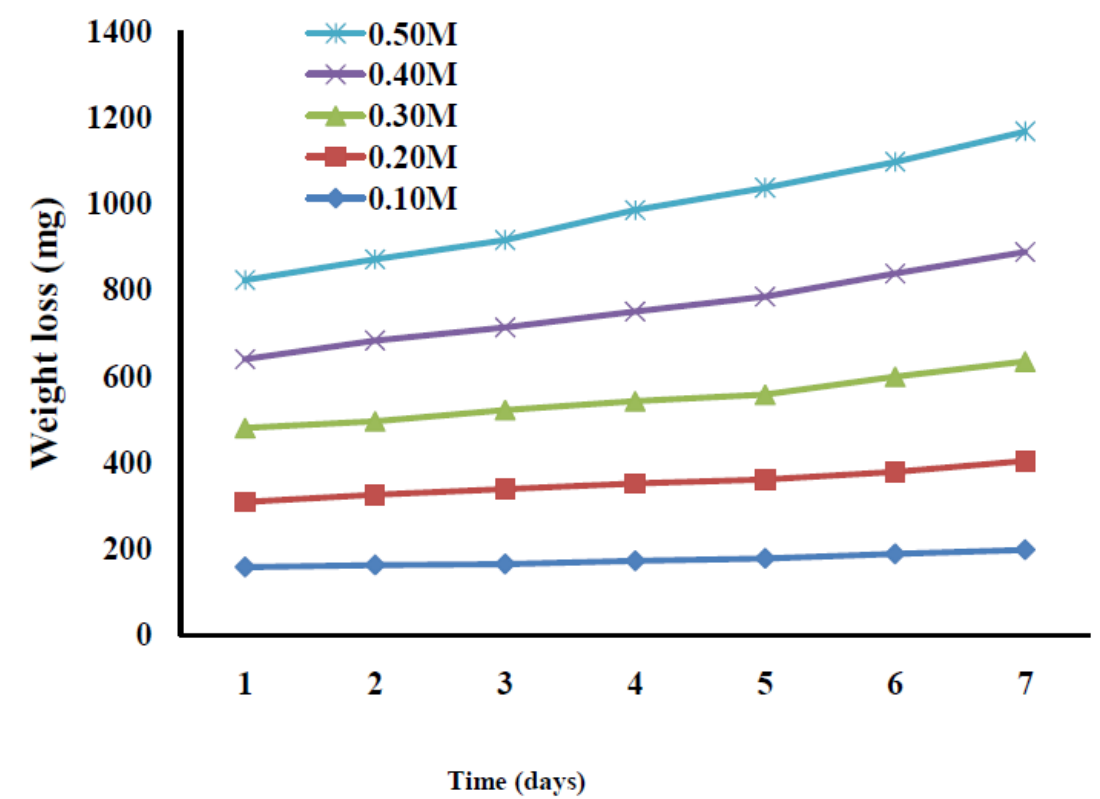

Figure1. Plot of Weight loss $\left(m g L^{-1}\right)$ versus time (days) for Brass Corrosion in various concentrations of $\mathrm{HCl}$ at $303 K$ 
Similar trend was observed at $313 \mathrm{~K}, 323 \mathrm{~K}$ and $333 \mathrm{~K}$ but with higher weight loss. This could be attributed to an increase in the rate of ionization and diffusion of active species in the corrosion process. More so, rates of chemical reactions increase with increasing acid concentration and temperature. Similar observation has been made by several workers on the corrosion of metals/alloys in $\mathrm{HCl}$ and $\mathrm{H}_{2} \mathrm{SO}_{4}$ solutions [7,15]. Increase in temperature favours the formation of copper $(11)$ chloride, $\mathrm{CuCl}^{2-}$ with $\mathrm{Cl}^{-}$ions which is also corrosive to brass.

Table1. Corrosion Parameters for Brass Corrosion in $0.5 \mathrm{M} \mathrm{HCl}$ containing Ficuscarica from Weight loss Measurements

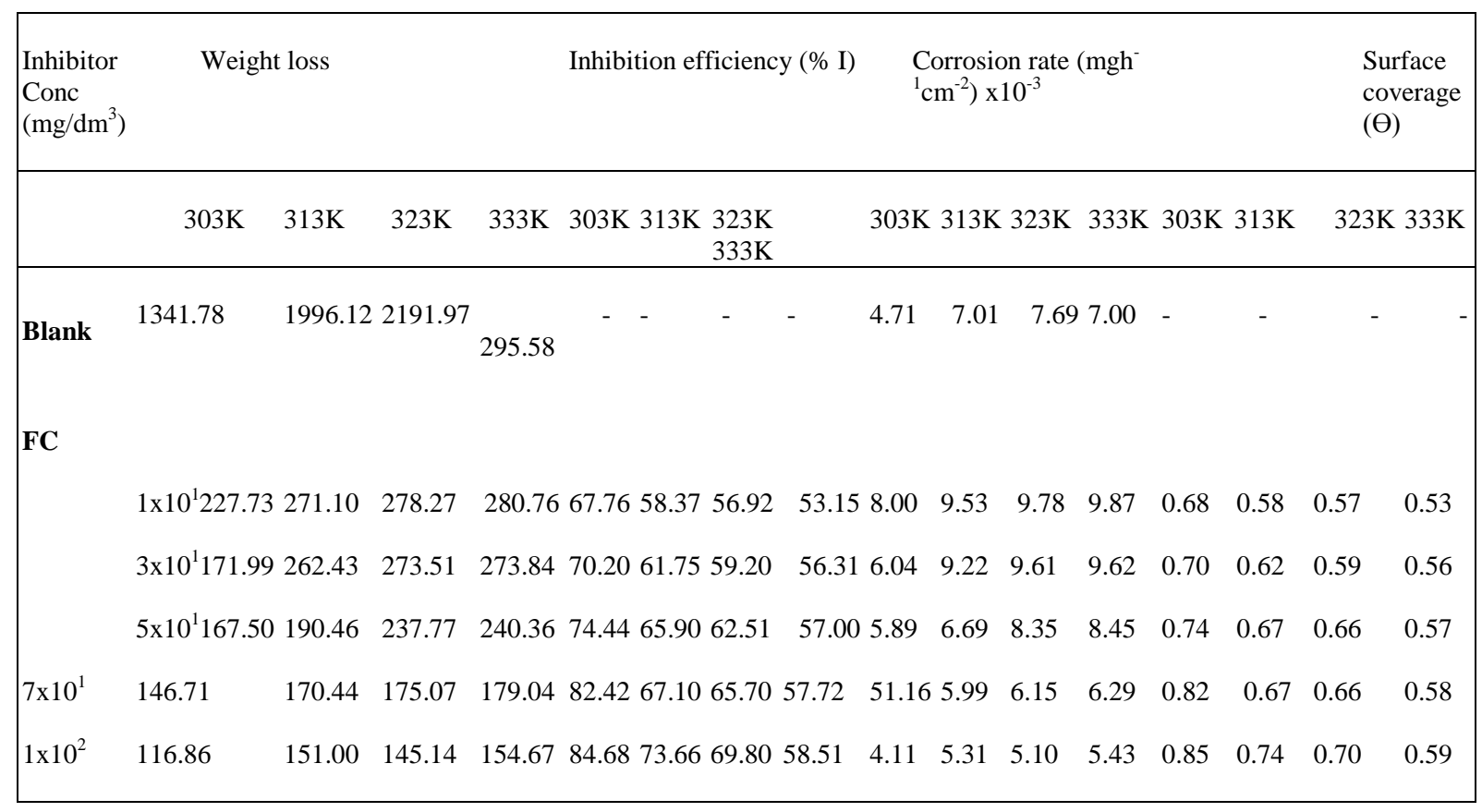

Table2. Corrosion Parameters for Brass in $0.50 \mathrm{M} \mathrm{HCl}$ containing Vitellariaparadoxa from Weight loss Measurements

\begin{tabular}{|c|c|c|c|c|c|c|c|c|c|c|c|c|c|c|c|c|}
\hline \multicolumn{3}{|c|}{$\begin{array}{l}\text { Inhibitor Conc. } \\
\left(\mathrm{mg} / \mathrm{dm}^{3}\right)\end{array}$} & \multicolumn{2}{|c|}{ Weight loss } & \multicolumn{4}{|c|}{ Inhibition efficiency (\% I) } & \multicolumn{4}{|c|}{$\begin{array}{l}\text { Corrosion rate }\left(\mathrm{mgh}^{-}{ }^{1} \mathrm{~cm}^{-}\right. \\
\left.{ }^{2}\right) \times 10^{-3}\end{array}$} & \multicolumn{4}{|c|}{ Surface coverage } \\
\hline & $303 \mathrm{~K}$ & $313 \mathrm{~K}$ & $323 \mathrm{~K}$ & $333 \mathrm{~K}$ & $303 \mathrm{~K}$ & $313 \mathrm{~K}$ & $323 \mathrm{~K}$ & $333 \mathrm{~K}$ & $303 \mathrm{~K}$ & $313 \mathrm{~K}$ & $323 \mathrm{~K}$ & $333 \mathrm{~K}$ & $303 \mathrm{~K}$ & $313 \mathrm{~K}$ & $323 \mathrm{~K}$ & $333 \mathrm{~K}$ \\
\hline $\begin{array}{l}\text { Blank } \\
\text { VP }\end{array}$ & 1341.78 & 1996.12 & 2191.97 & 2195.5 & - & - & - & - & 4.71 & 7.01 & 7.70 & 7.71 & - & - & - & - \\
\hline $1 \times 10^{1}$ & 260.46 & 265.79 & 279.10 & 279.86 & 61.29 & 56.90 & 54.95 & 54.10 & 9.15 & 9.34 & 9.81 & 9.83 & 0.61 & 0.57 & 0.55 & 0.54 \\
\hline $3 \times 10^{1}$ & 242.44 & 260.10 & 276.47 & 279.70 & 62.32 & 58.40 & 57.13 & 56.21 & 8.52 & 9.14 & 9.71 & 9.83 & 0.62 & 0.58 & 0.57 & 0.56 \\
\hline $5 \times 10^{1}$ & 218.31 & 251.58 & 233.24 & 234.26 & 65.95 & 59.20 & 58.00 & 57.23 & 7.67 & 8.84 & 8.20 & 8.23 & 0.66 & 0.59 & 0.58 & 0.57 \\
\hline $7 \times 10^{1}$ & 176.09 & 167.39 & 229.33 & 228.06 & 70.16 & 68.88 & 67.03 & 62.40 & 6.19 & 5.88 & 7.96 & 8.01 & 0.70 & 0.69 & 0.67 & 0.62 \\
\hline $1 \times 10^{2}$ & 153.76 & 162.74 & 209.96 & 215.99 & 77.66 & 72.33 & 70.30 & 68.20 & 5.40 & 5.72 & 7.36 & 7.59 & 0.78 & 0.72 & 0.70 & 0.68 \\
\hline
\end{tabular}

\subsection{Effect of Ficuscarica and Vitellariaparadoxa Concentrations on Brass Corrosion}

Figures 3 and 4 show the plots of weight loss against time (days) for brass corrosion in $0.5 \mathrm{M} \mathrm{HCl}$ with various concentrations of FC and VP respectively at 303K. Similar plots were obtained at 313, 323 , and $333 \mathrm{~K}$ but with higher weight losses. The plots reveal that the weight loss was lowest at $100 \mathrm{mgdm}^{-3}$ (highest concentration of the inhibitors studied) on brass. This indicates that the inhibitors, FCandVP actually inhibited the corrosion of brass with the efficiency increasing from FC to VP concentrations and at low temperatures. 


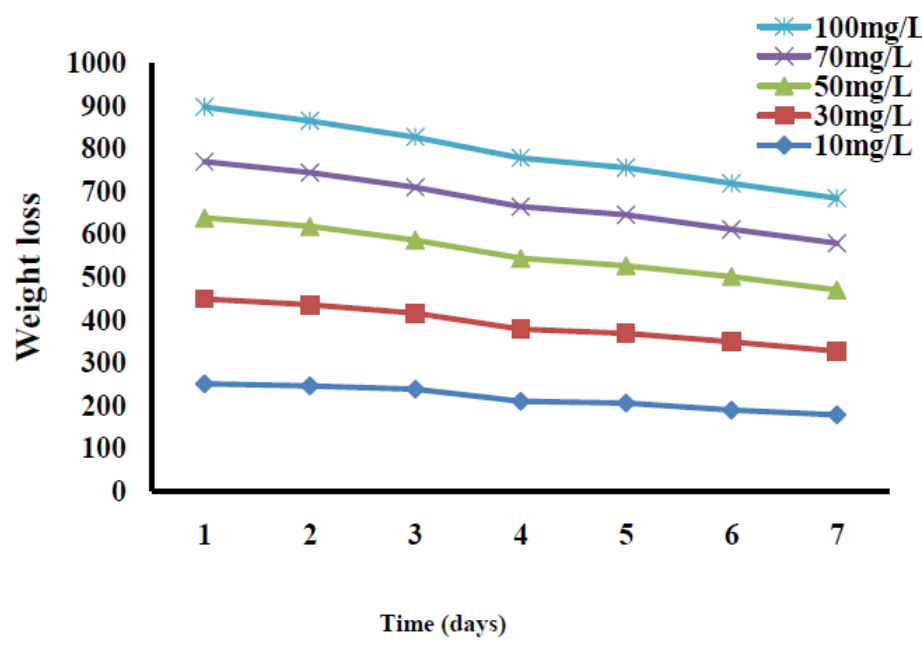

Figure3. Plot of weight loss against time for brass coupons in $0.5 \mathrm{M} \mathrm{HCl} \mathrm{containing} \mathrm{various} \mathrm{concentrations} \mathrm{of}$ FC at $303 \mathrm{~K}$

With the addition of the inhibitors, FC and VP extracts, corrosion rates decreased while the inhibition efficiency and surface coverage increased significantly with increasing concentration. However, inhibition efficiency and surface coverage decreased with increasing temperature (303-333K) with a maximum at $91.34 \%, 89.83 \%, 82.40 \%$, and $80.58 \%$ at $303,313,323$ and $333 \mathrm{~K}$ respectively. This implies that the inhibitors, FC and VP function better at lower temperatures which suggest physisorption. The decrease in inhibition efficiency with increasing temperature shows that the time lag for the adsorption of FC and VP molecules on brass surface becomes shorter. This assertion agrees with the findings of $[4,5]$. The behaviour of the inhibitors at $303 \mathrm{~K}$ may be attributed to the adsorption of the inhibitors up to $313 \mathrm{~K}$ and a further increase in temperature brings about desorption of the inhibitors (FC and VP). This may be due to the fact that adsorption and desorption of the inhibitor molecules continuously occur at brass surface, resulting in equilibrium between these two processes at a particular temperature. With a further increase in temperature, the equilibrium between adsorption and desorption process is shifted leading to a higher desorption rate than adsorption until equilibrium is again established at a different value of equilibrium constant. It explains the lower inhibition efficiency at higher temperature. This assertion is in agreement with studies by earlier workers [15].

\subsection{Adsorption Consideration of the Results}

From Tables 1, 2 and 3, 4 and figure 5, it is evident that the inhibition efficiency and surface coverage increases with increasing inhibitor concentration and decrease with increasing temperature, from 303$333 \mathrm{~K}$. This is suggestive of physical adsorption. This assertion is in good agreement with observations made earlier by Eddyet al[13] and Onenet al [14]. Figure 5 also shows that the plot of isotherm of higher temperature $(333 \mathrm{~K})$ is under that of lower temperature $(303 \mathrm{~K})$. This further confirms physical adsorption for the inhibition process.

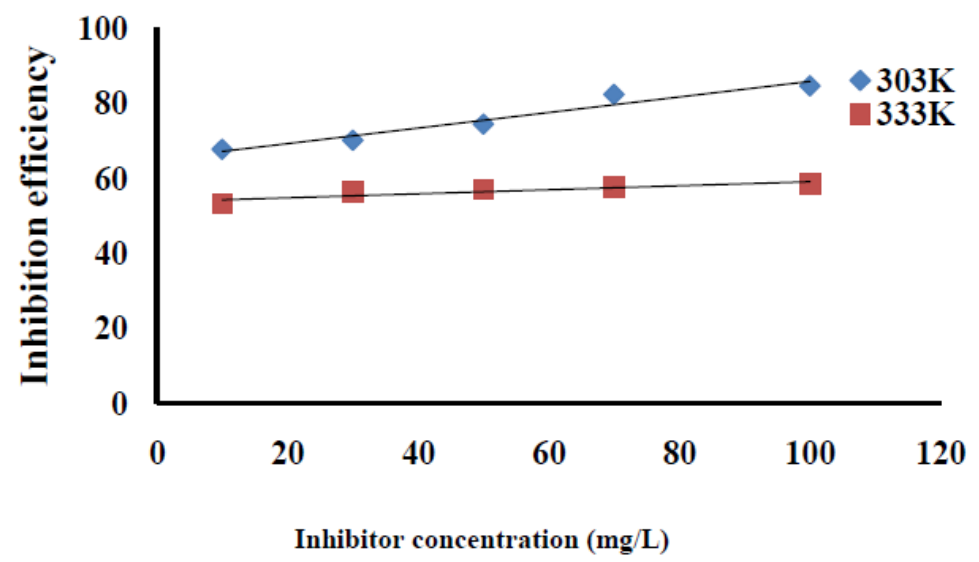

Figure5. Plot of inhibition efficiency (\%I) versus inhibitor (FC) concentration for Brass at $303 \mathrm{~K}$ and $333 \mathrm{~K}$

To establish the extent of adsorption of inhibitor molecules on brass surface, some adsorption isotherms were plotted. The linear plot obtained from the graphs of ' $\mathrm{C}$ ' $/ \theta$ against ' $\mathrm{C}$ ' at 303 and $333 \mathrm{~K}$ 
(figure 7) shows that the experimental data obtained within the temperature range fits Langmuir adsorption isotherm. In a similar way, a plot of surface coverage $(\theta)$ versus inhibitor concentration (' $\mathrm{C}$ ') gave a straight line (figure 6) indicating that Frumkin isotherm is obeyed. This confirms that corrosion inhibition is often due to formation and maintenance of a thin protective layer on the metal surface.

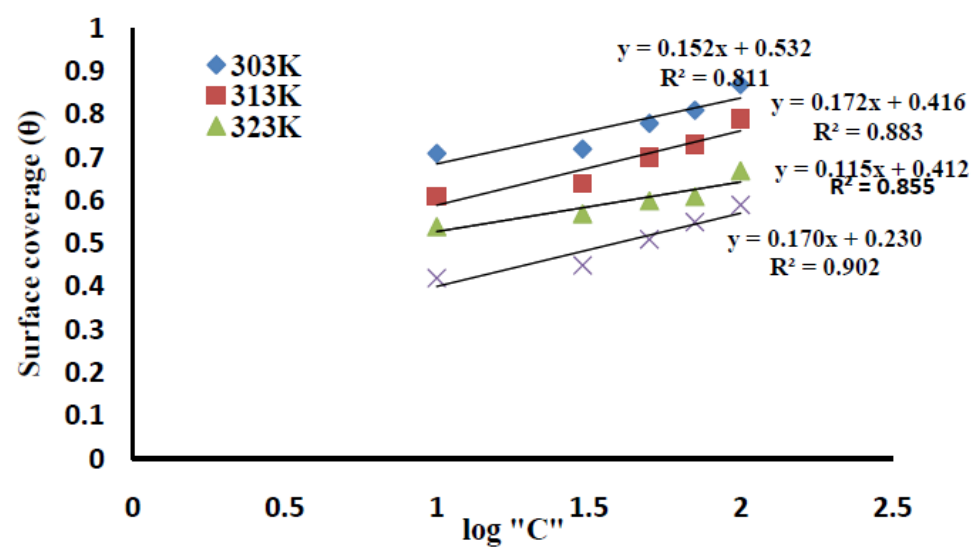

Figure6. Frumkin adsorption isotherm plotted as " $\theta$ " versus log "C" for Brass corrosion inin 0.5MHCl containing different concentrations of FC at $303 \mathrm{~K}$

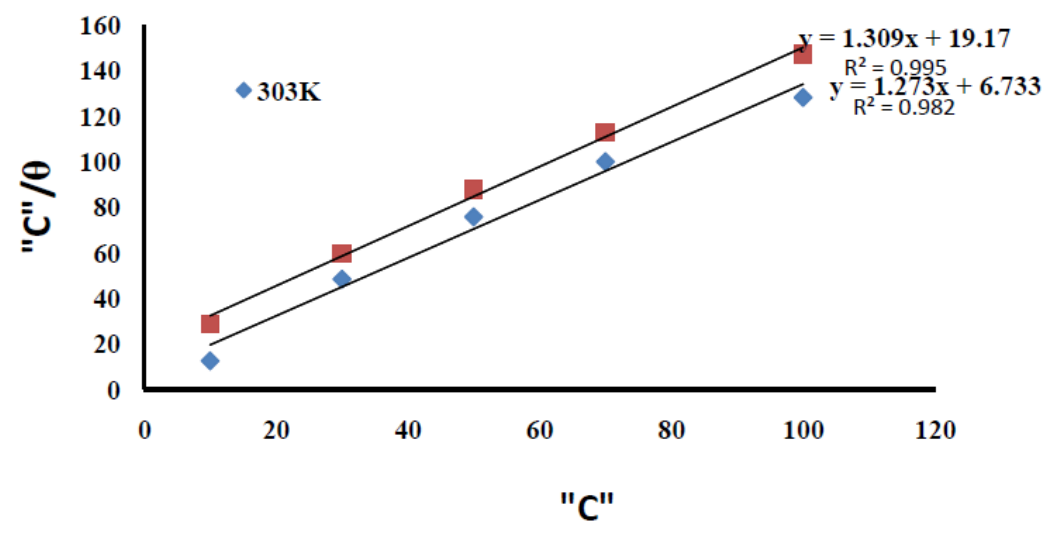

Figure 7: Langmuir isotherm plotted as " $\mathrm{C}$ "/ $\theta$ versus " $\mathrm{C}$ " for aluminium corrosion in $0.5 \mathrm{MHCl}$ containing different concentrations of $\mathrm{CC}$ at $303 \mathrm{~K}$

Table3. Some kinetic data for Brass corrosion in $0.5 \mathrm{M} \mathrm{HCl}$ containing FicuscaricaandVitellariaParadoxafrom Weight loss measurement

\begin{tabular}{|c|c|c|c|c|c|c|c|}
\hline \multicolumn{2}{|c|}{ Inhibitor Conc $(\mathrm{mg} /)$} & \multicolumn{2}{|c|}{ Rate Constant $\left(\mathrm{s}^{-1}\right)$} & \multicolumn{2}{|c|}{$\begin{array}{l}\text { Half-life, } t_{1 / 2}(\mathrm{sec} .) \\
\left.{ }^{1}\right)\end{array}$} & \multicolumn{2}{|c|}{ Activation Energy, $\mathrm{Ea}(\mathrm{kJmol}$} \\
\hline & & $303-313 \mathrm{~K}$ & $323-333 \mathrm{~K}$ & $303-313 \mathrm{~K}$ & $323-333 \mathrm{~K}$ & $303-313$ & $323-333 \mathrm{~K}$ \\
\hline Blank & & & & & & 15.56 & 15.71 \\
\hline FC & & & & & & & 15.86 \\
\hline $1 \times 10^{1}$ & & $1.06 \times 10^{-2}$ & $1.56 \times 10^{-2}$ & $6.54 \times 10^{1}$ & $4.44 \times 10^{1}$ & 15.85 & 15.38 \\
\hline $3 \times 10^{1}$ & & $1.58 \times 10^{-2}$ & $2.13 \times 10^{-2}$ & $4.39 \times 10^{1}$ & $3.25 \times 10^{1}$ & 15.31 & 14.97 \\
\hline $5 \times 10^{1}$ & & $2.03 \times 10^{-2}$ & $2.23 \times 10^{-2}$ & $3.41 \times 10^{1}$ & $3.1 \times 10^{1}$ & & \\
\hline $7 \times 10^{1}$ & & $2.42 \times 10^{-2}$ & $2.51 \times 10^{-2}$ & 15.31 & & & 14.91 \\
\hline $1 \times 10^{2}$ & & $3.37 \times 10^{-2}$ & $3.77 \times 10^{-2}$ & $2.86 \times 10^{1}$ & $2.76 \times 10^{1}$ & 14.78 & 14.79 \\
\hline Mean & 14.96 & 15.25 & & $2.06 \times 10^{1}$ & $1.84 \times 10^{1}$ & 13.91 & \\
\hline VP & & & & & & & \\
\hline $1 \times 10^{1}$ & & $1.13 \times 10^{-2}$ & $1.57 \times 10^{-2}$ & & & & 15.98 \\
\hline $3 \times 10^{1}$ & & $1.42 \times 10^{-2}$ & $1.72 \times 10^{-2}$ & $6.13 \times 10^{1}$ & $4.41 \times 10^{1}$ & 15.85 & 15.75 \\
\hline $5 \times 10^{1}$ & & $2.02 \times 10^{-2}$ & $1.77 \times 10^{-2}$ & $4.88 \times 10^{1}$ & $4.03 \times 10^{1}$ & 15.51 & 14.79 \\
\hline $7 \times 10^{1}$ & & $2.15 \times 10^{-2}$ & $2.03 \times 10^{-2}$ & $3.43 \times 10^{1}$ & $3.92 \times 10^{1}$ & 14.98 & 14.38 \\
\hline $1 \times 10^{2}$ & & $3.63 \times 10^{-2}$ & $3.83 \times 10^{-2}$ & $3.22 \times 10^{1}$ & $3.41 \times 10^{1}$ & 14.78 & 14.85 \\
\hline Mean & 15.13 & 15.15 & & $1.91 \times 10^{1}$ & $1.81 \times 10^{1}$ & 14.51 & \\
\hline
\end{tabular}




\subsection{Kinetic Consideration}

The activation energy values presented in Tables 3 were obtained from the plots of the logarithm of rate constant (k) against the inverse of temperatures understudy (303, 313, 323 and 333K). The slope of the line multiplied by the ideal gas constant $\mathrm{R}$ gives the activation energy, $\mathrm{E}_{\mathrm{a}}$. The activation energy of the inhibited solution decreases by increasing the concentration of Ficuscarica and Vitellariaparadoxa. This finding indicates that this inhibitor retards the corrosion of brass in the studied media $(\mathrm{HCl})$.

The values of rate constants, $\mathrm{k}$ also recorded in Table 3 were obtained from plots of $\log \mathrm{W}_{\mathrm{L}}$ versus time (days) in $\mathrm{HCl}$ solutions (plots not shown) while the half-life, $\mathrm{t}_{1 / 2}$ were determined from the expression:

$\mathrm{t}_{1 / 2}=0.693 / \mathrm{k}$.

The observed linearity from the plots reveals first order kinetics for the inhibition process. The rate constant, $\mathrm{k}$ decreases with increase in concentration of all the inhibitors while the half-life increases with increasing inhibitors concentration. These observations further confirm the fact that the inhibition process follows first order kinetics.

\subsection{Comparative Studies of Inhibitory Actions of Ficuscarica and Vitellariaparadoxa}

The results obtained in this study (Tables 1-2) show the order of increase of the inhibition efficiency of the plants extracts: FC $(84.68 \%)>$ VP $(77.66 \%)$ using weight loss measurements. The inhibition effectiveness of the leaf extracts of Ficuscarica and Vitellariaparadoxa has been attributed to the presence of alkaloids, glycosides, flavonoids, saponins, tannins e.t.c (containing $-\mathrm{C}=\mathrm{N},-\mathrm{C}=\mathrm{O}, \mathrm{C}=\mathrm{C}$, $\mathrm{C}-\mathrm{OH} \mathrm{OH},-\mathrm{CH}_{3}$ ). From the values of inhibition efficiencies given above, it suffices to say that Ficuscarica showed better inhibitory action on brass surface at all concentrations and temperatures studied. Similarly, the weight loss values were lower in Ficuscarica leaf extracts than Vitellariaparadoxa which further reveals that Ficuscarica showed better performance on brass surface than Vitellariaparadoxa..

\section{Conclusion}

The inhibitors, FC and VP investigated inhibit the acid corrosion of brass with inhibition efficiency (\%I) increasing with concentration but decreasing with temperature. From the Ea values obtained, the mechanism of physical adsorption was proposed for the inhibition process. The adsorption of Ficuscarica and Vitellariaparadoxa on brass surface in $0.5 \mathrm{M} \mathrm{HCl}$ fit into Frumkin and Langmuir adsorption isotherms.

\section{REFERENCES}

[1] F. M .Kharafi, B. G .Ateya and R .M .Abdallah (2004).Selective dissolution of Brass in salt water.J ApplElectrochemSci; 34.47-60.

[2] M. A. Milan, M. M. Snezana and B. P. Marija (2009). Films formed on Copper surface in Chloride Media in the presence of Azoles. Corros Sci., 51. 1228 - 1239.

[3] M. M .Antonijevic, G .D. Bogdanovic and M .B. Radovanovic (2009). Influence of pH and Chloride Ions on Electrochemical Behaviour of Brass in Alkaline Solution. Inter $J$ ElectrochemSci;.4. $654-661$.

[4] T.TareqBataineh Mahmoud A. Al-QudahEyad M. NawaflehNathir A.F. andRawashdeh (2014)Sinapis Alba Extract as Green Corrosion Inhibitor for Aluminum in Alkaline Media. InterJElectrochemSci9. 3543 - 3557.

[5] A .I. Onen (2004). Inhibition of acidic corrosion of Mild Steel by Opuntia SPP (OSPP), Cactus milk extract.Nigerian J Appl Sci., 22.174 - 181.

[6] O .K. Orubite and N .C .Oforka (2004). Inhibition of Corrosion of Mild Steel in HCl Leaves extract of NypaFruticansWurmb.Mater Letts; 58(11). 1768 - 1778.

[7] A .I. Onen and B .T. Nwufo (2008). Cassia Siamea Lam Leaves extract as a corrosion inhibitor of Mild Steel in $\mathrm{H}_{2} \mathrm{SO} 4$ Solutions. Inter J Chem; 18 (2). 77 - 87.

[8] A .I. Onen (2009). Corrosion Inhibition of Corrugated Zinc in Hydrochloric acid solutions using bark extract ofCassia Siamea Lam.Inter J Chem;1(1). 22 - 29. 
[9] I. H. Ali (2016).Inhibitory Effect of Leaf Extract of Khayasenegalensis (Mahogany) on C-steel Corrosion in 1.0 M Hydrochloric Acid Solution Inter J ElectrochemSci11: 2130 -2141

[10] C. Perez, J .R. Canal, A. Campillo, A. Romero and M .D. Torres (1999). Hypotriglyceridemic activity of Ficus Carica leaves in experimental Hypertriglyceridemic rats. Phytochem Res. 181 191

[11] S. Maranz, Z. Wiesman, J. Bisgaard and G. Bianchi (2004).Germplasm resources of VitellariaParadoxa based on variations in fat composition across the species distribution range.Agrosforestrysyst; $\mathbf{6 0 . 7 1 - 8 0 .}$

[12] I .G. Ndukwe, J .O. Amupitan and Y. Zhao (2007). Isolation and characterization of 3,5, 6trihydroxy-7-Octyl -5-6 dihydroxy-1-naphthalene Carboxylic acid from the stem Methanol extract of VitellariaParadoxa.J Med pl Res; 2007. 1(3).60-63.

[13] N .O. Eddy, U .J. Ibok, E .E. Ebenso, A. El Nemr, H. El Sayed, and E. El Ashry (2009). Quantum Chemical Study of the inhibition of the corrosion of Mild Steel in $\mathrm{H}_{2} \mathrm{SO}_{4}$ solution by some Antibiotics. J Mol Model.15. 1085- 1092

[14] A .I. Onen, O .N. Maitera, J. Jacob and E .E. Ebenso (2011). Corrosion Inhibition Potential and Adsorption Behaviour of Bromophenol Blue and Thymol Blue Dyes on Mild Steel in Acidic Medium. Inter J ElectrochemSci;.6. 2884-2807.

[15] D. Nalini, R. Rajalakshmi and S. Subhashini (2011). Corrosion Inhibition of mild Steel in Acid solution by 3, 4, 5-Trimethoxyphenyl-2-imidazolines. E-J Chem; 8(2). 671-679. 